\title{
Los caníbales: una lectura desde Maquiavelo y Montaigne *
}

\author{
The cannibals: a reading from Machiavelli and Montaigne
}

Por: Mattei, Eugenia

Universidad de Buenos Aires-IIGG/CONICET

Buenos Aires, Argentina

Correo electrónico: e.mattei@conicet.gov.ar

ORCID: https://orcid.org/0000-0001-5158-7161

Fecha de recepción: 9/03/2021

Fecha de aprobación: 14/05/2021

DOI: $\underline{\text { http://dx.doi.org/10.30972/nvt.1715357 }}$

\section{Resumen}

En el presente artículo se aborda el hilo que conecta a Nicolás Maquiavelo y a Michel de Montaigne a través de la presencia de los caníbales. ¿Por qué los caníbales? Los caníbales es el arquetipo en el cual se construye "el otro", "lo bárbaro", "lo salvaje", "lo incivilizado" y "lo poco ilustrado". En el modo en el cual Maquiavelo y Montaigne tematizan dicha figura, se puede dilucidar cómo estos autores entienden las relaciones políticas. En este sentido, el artículo está dividido en cuatro partes: en la primera, se presenta la introducción al tema y se aborda de modo sucinto la literatura especializada; en la segunda parte, se analiza la tematización que hicieron tanto Montaigne como Maquiavelo sobre la fuerza que ejercen las costumbres en los hombres; una vez realizado esto, se analiza en la tercera parte la figura de los caníbales

\footnotetext{
* Agradezco la lectura y los comentarios de Francisco Hermo a versiones preliminares de este artículo y las observaciones que señaló un evaluador/a anónimo. Asimismo, este trabajo es tributario de las discusiones que mantuve con les participantes del grupo de lectura sobre Montaigne durante el 2020

* Eugenia Mattei es Dra. en Ciencias Sociales (Universidad de Buenos Aires), Mag. en Ciencia Política (IDAES-UNSAM) y Lic. En Ciencia Política (FSOC-UBA) con orientación teoría política. Actualmente es investigadora asistente de CONICET y del Instituto de Investigaciones Gino Germani. Asimismo, se desempeña como jefa de trabajo prácticos de Fundamentos de Ciencia Política I (UBA-FSOC) y es miembro del comité editorial de la Revista Argentina de Ciencia Política. Correo electrónico: e.mattei@conicet.gov.ar.
} 
en ambos autores; por último, se presentan las conclusiones del trabajo de investigación realizado.

Palabras clave: antropofagia; costumbres; sujeción política; relaciones sociales y políticas; mundo americano.

\section{Abstract}

The aim of this article is to analyze the thread that connects Nicolas Machiavelli and Michel de Montaigne through the presence of cannibals. Why the cannibals? The cannibals are the archetype in which "the other", "the barbarian", "the wild", "the uncivilized" and "the little enlightened" are built. In the way in which Machiavelli and Montaigne thematize this figure, it is possible to elucidate how these authors understand political relations. In this sense, the article is divided into four parts: in the first, the introduction to the subject is presented and the specialized literature is briefly addressed; In the second part, the thematization made by both Montaigne and Machiavelli about the force that customs exert on men is analyzed; Once this is done, the figure of cannibals in both authors is analyzed in the third part; Finally, the conclusions of the research work carried out are presented.

Keywords: anthropophagy; customs; political subjection; social and political relations; American world.

\section{Cómo citar este artículo:}

APA: Ighina, D. (2021). Los caníbales: una lectura desde Maquiavelo y Montaigne. Nuevo Itinerario, 17 (2), 260-283.

\section{A modo de introducción: Montaigne lector de Maquiavelo}

Nicolás Maquiavelo (1469-1527) y Michel de Montaigne (1533-1592) son dos pensadores de tiempos de guerra. Como recuerdan Jean-Louis Fournel y Jean- Claude 
Zancarini (2020), Maquiavelo fue parte de una generación marcada por las guerras en Italia. Aquellos conflictos bélicos conducidos por Francia y España durante treinta años sobre el sur y el norte de la península itálica son un ejemplo de ello. Dicha tensión prevaleció hasta la batalla de Pavía, en febrero de 1525, recordada como un gran fracaso militar de Francia por parte de España. Muy cerca del fallecimiento de Maquiavelo -el 21 de junio de 1527-, el saqueo de Roma por parte de las tropas alemanas y españolas terminó por consagrar la victoria imperial en mayo del mismo año. Como una especie de sincronía, Montaigne fue parte de una generación que se enfrentó al problema de las guerras: ¿De qué tipo de cristianismo había que ser parte? ¿el católico o el protestante? En París, la noche del 23 de agosto de 1572 comenzó una gran cantidad de asesinatos de protestantes que posteriormente se extendió a lo largo de Francia. Este hecho atávico conocido como la masacre de San Bartolomé dejó un total de 20.000 víctimas (Skinner, 1978) y "puso el fin a la tregua entre el Rey Carlos IX y su madre Catalina de Medici tras la tercera guerra religiosa entre católicos y protestantes franceses, conocidos como hugonotes" (Nosetto, 2020, p. 184). El mundo que tanto Maquiavelo como Montaigne habitaron era un mundo viejo que se resistía a morir y uno nuevo que todavía no terminaba de nacer.

Del Maquiavelo joven se sabe muy poco, solo que pertenecía a una familia del "Popolo grasso", de Florencia del siglo XII y, según el Libro di ricordi (2007), los recursos económicos del padre de Maquiavelo eran más bien modestos. Éstos provenían de contratos con agricultores arrendatarios de propiedades en Sant'Andrea en Percussina. Montaigne, por el contrario, provenía de una familia noble reciente. Su padre, Pierre Eyquem, era un caballero cuyos antepasados eran comerciantes de vino y propietarios de tierras cercanas a Burdeos y su madre, Antoinette de Loupes, una figura menos presente en los Ensayos, era de origen español y se cree que también judío converso (Burke, 1985).

Acerca de la compleja relación entre política y filosofía, ambos hombres realizaron una particular alquimia. A diferencia de la vida del joven Maquiavelo, del Maquiavelo político se sabe mucho: el 28 de mayo de 1498 fue nombrado segundo Canciller por el Consiglio dei Richiesti; luego, en junio, secretario de la segunda 
Cancillería y en julio del mismo año secretario de los Diez de Libertad y Paz. Es decir, todos esos cargos parecen mostrar que Maquiavelo tenía un protagonismo en la vida palaciega. No obstante, como todo lo que sube en algún momento baja, con el regreso de los Médici al poder en Florencia, el 7 de noviembre de 1512, fue despojado del cargo y finalmente arrestado el 13 de febrero de 1513 al ser acusado de participar en un complot. A razón de esta circunstancia permaneció en la cárcel hasta el 12 de marzo gracias a una amnistía brindada por el Papa León X. Posteriormente, se vio obligado al exilio político en su casa de campo en Sant'Andrea en Percussina. Y ahí, en el conocido Albergaccio es donde escribió sus obras más difundidas. Al respecto, puede indicarse la famosa carta de Maquiavelo a su amigo, Francesco Vettori, el 10 de diciembre de 1513 en la cual se muestra el vínculo que mantiene el florentino con los autores clásicos en su ostracismo político (Maquiavelo, 2013, pp. 134-139). Cuando obtuvo la autorización, retornó a Florencia para nunca más volver a ser funcionario (Bausi, 2015; Vivanti, 2013; Viroli, 2000).

Montaigne también estuvo vinculado a la política, pero de un modo más espasmódico: fue conseiller en el tribunal de Burdeos de 1557 a 1570 y fue dos veces alcalde de la misma ciudad entre 1581 y 1585 . En 1580 se fue de viaje de Italia porque pensaba que lo iban a nombrar embajador. Sin embargo, eso no ocurrió porque designaron a otra persona y obtuvo, como forma de premio consuelo, la ciudadanía romana y la alcaldía de Burdeos (Desan, 2016, pp. 166-191). En la decena de años que separa su actividad política convulsionada por las guerras religiosas, vendió su puesto de magistrado y se retiró a su castillo heredado por la muerte de su padre para seguir leyendo a los clásicos. Este retiro de los asuntos públicos le permitió dedicarse a administrar las propiedades y a la escritura de los Ensayos ${ }^{1}$.

Que Maquiavelo y Montaigne son muy diferentes es un rasgo que emerge de esta descripción. Sin embargo, hay algo que los une. El hilo más evidente abordado por

\footnotetext{
${ }^{1}$ Durante su vida Montaigne público dos ediciones de los Ensayos: la de los libros I y II en 1580, y la de los libros I, II y III, con agregados en los primeros dos libros en 1588. Posteriormente, hizo agregaciones a los márgenes de libro hasta su muerte en 1592 Marie de Gournay publicaría la edición de 1595, que comprende adiciones y que difiere muy poco del texto de 1588. En muchas partes de los Ensayos celebra la actividad de la lectura por ser el lugar en donde reinan el ocio y la libertad: "Me conformo con gozar del mundo, sin ocuparme de él, y vivir una vida solo perdonable y que no pese ni a mí ni a los demás" (Montaigne, 2011, p. 854).
} 
la literatura especializada es aquel que muestra a Montaigne como lector de Maquiavelo. En los Ensayos hay dos claras referencias explícitas a Maquiavelo que dan cuenta que Montaigne efectivamente estaba familiarizado con la obra del autor italiano.

Estas referencias a Maquiavelo se encuentran en el ensayo denominado "De la presunción" (II.17) y en el ensayo conocido como "Observaciones de Julio César sobre el modo de hacer la guerra" (II.34). En "De la presunción", Montaigne rehúye a cualquier definición de sí mismo. Dice que sabe sostener "una opinión, pero no elegirla" pero también afirma que prefiere "la duda y la libertad de elegir" hasta que la ocasión lo obligue a tomar una elección (Montaigne, 2011: 597). En esa situación de indefinición, Montaigne admite que se abandona "a la merced de la fortuna". Seguidamente, afirma que prefiere dejarse llevar por la multitud porque no confía en su capacidad de poder guiar. Prefiere, en este sentido, seguir los pasos señalados por otros que estén más seguros de sus opiniones. Pero luego, admite que le resulta fácil cambiar de opinión y que nota que su propia debilidad (es decir, que sus opiniones tengan un fundamento resbaladizo) también se encuentra en las opiniones contrarias. La escritura de Montaigne es sinuosa: posee pliegues y cualquier afirmación es seguida por su negativa.

Esto, lejos de ser una disposición individual, es parte de la condición humana y marca el modo en el cual los hombres hacen política. Para Montaigne, la política es un "campo abierto al movimiento y la contestación" y es aquí donde aparece por primera vez Maquiavelo:

Los discursos de Maquiavelo, por ejemplo, eran bastante sólidos para el tema ${ }^{2}$, y sin embargo ha habido gran facilidad para combatirlos; y los que lo han hecho no han ofrecido menos facilidad para combatir los suyos. Siempre se encontrarán, para su argumento cualquiera, el medio de proveer réplicas, contrarréplicas, dúplicas, tríplicas, y esa infinita maraña de debates que nuestras chicanas alargan en tanto pueden favorecer procesos" (Montaigne, 2011, p. 598)

\footnotetext{
${ }^{2}$ Es, decir los asuntos políticos.
} 
Los discursos de Maquiavelo, entonces, son sólidos. Pero también encuentran sus réplicas y, a su vez, a la postura antimaquiaveliana se la puede criticar. Es decir, nada puede sostenerse con certeza ${ }^{3}$. Tanto Sylvia Sanders (1976) como Oana-Alis Zaharia (2014) señalan que resulta llamativo el tono que posee esta referencia a Maquiavelo. Montaigne parece tomar una actitud neutral frente a un autor que era visto en aquella época como el maestro del mal. En 1576, el hugonote Innocent Gentillet (1535-1588) condenaba a Maquiavelo por ser un exaltador de las crueldades en política en su texto Anti-machiavel. Como bien señala Claude Lefort (1986), El príncipe termina siendo el marco teórico de la política de Catalina de Médicis supuestamente plasmada en la masacre de la noche San Bartolomé en agosto de 1572. Por eso, llama mucho la atención que, en este mismo ensayo, se dedica hablar de los "deberes de un príncipe", y no se indigna cuando el príncipe rompe su palabra dada:

Aquellos que en nuestros tiempos han considerado en la definición de los deberes de un príncipe el solo bien de los asuntos y lo prefieren por sobre el cuidado de su palabra y conciencia, aprobarían a un príncipe a quien la fortuna hubiera arreglado los asuntos de tal modo que pudiera asegurarlos por una sola vez de faltar a su palabra. Pero las cosas no son así. Siempre se recae en actitudes semejantes, pues en la vida se firma más de una paz, más de un tratado. El beneficio que los lleva a la primera deslealtad se presenta casi siempre como todas las demás maldades: los sacrilegios, los crímenes, las rebeliones, las traiciones, se emprenden por alguna clase de provecho, pero esa primera ganancia aporta infinitos daños posteriores arrojando a ese príncipe fuera de toda sociedad y medio de negociación a causa del precedente de aquella infidelidad (Montaigne, 2011, pp. 592-593).

En "Observaciones de Julio César sobre el modo de hacer la guerra la referencia” (II.34) es más ambigua que la anterior. Maquiavelo se encuentra en el mismo párrafo que las menciones a Alejandro, Homero, Escipión, Jenofonte, Marco Bruto, Polibio, Carlos V y Felipe de Comines. En ese contexto en donde se da cuenta de la popularidad de ciertos libros sobre líderes militares, Montaigne afirma que:

\footnotetext{
${ }^{3}$ Acá se observa de modo muy visible la condición escéptica de Montaigne. Agradezco a Francisco Hermo haberme señalado esto.
} 
en estos tiempos se dice que Maquiavelo aún tiene prestigio en otras partes, pero el finado mariscal Strozzi que por su parte había adoptado a César, sin dudas eligió mucho mejor; pues en verdad este debería ser el breviario de todo hombre de guerra como verdadero y soberano patrono del arte militar (2011, pp. 663-644).

Esta referencia a Maquiavelo resulta muy insinuante porque ilustra la ambivalencia que genera su figura. Por una parte, Montaigne señala que muchos generales se apoyaron en conocimientos tomados de libros y menciona que hay gente que lee a Maquiavelo, pero dice que harían mejor en leer a César como hacía Piero Strozzi (1510-1558) - primo de la reina Catalina de Médici y el gran militar al servicio de Francia. Al decir esto, Montaigne está rechazando a Maquiavelo a favor de César como autor ${ }^{4}$.

Por otra parte, hay algo que se dice al pasar pero que es muy sintomático: "se dice que Maquiavelo aún tiene prestigio en otras partes"; o sea, no en Francia, donde se suscribe al antimaquiavelismo (recordemos que 1576 es el año de la publicación de Anti-Machiavel de Gentillet). Si bien esto último haría pensar que Montaigne comparte ese lugar común porque reproduce el "se dice..." y también pone que es mejor leer a César al menos en estos temas militares, hay que recordar la cita del otro ensayo en la cual afirma que Maquiavelo tenía sólidos argumentos y que la crítica antimaquiaveliana también le parecía pasible de ser criticada.

¿Cómo debemos comprender todo este rodeo? En principio, estas referencias parecen demostrar dos cosas: primero, Montaigne observa cosas relevantes en Maquiavelo (Maquiavelo es sólido en temas políticos); segundo, también observa cuestiones razonables en las críticas a Maquiavelo y argumenta que es mejor leer a César sobre cuestiones militares. En definitiva, Montaigne afirma y reniega de Maquiavelo. Y en ese juego se revela lo que parece ser más propio de Montaigne: no ser maquiaveliano o antimaquiaveliano, sino, más bien, mostrarse como un escéptico. En este sentido, es bastante significativo el hecho de que cuando menciona la cuestión

\footnotetext{
${ }^{4}$ En la cronología de la edición de El Acantilado figura que Montaigne leyó a César en 1578. Estimamos que se hace referencia a Comentarios sobre la guerra de las Galias. (Montaigne, 2017)
} 
Maquiavelo-Antimaquiavelo, no lo hace para tomar partido por uno de esos bandos. Lo usa de ejemplo para señalar que a cualquier discurso político se le puede oponer otro igual de convincente y, en definitiva, esto también es lo mismo que dice sobre las opiniones en general.

A partir de esta reconstrucción que evidencia que Montaigne leyó a Maquiavelo, es posible reconstruir en la literatura especializada tres tipos de abordajes acerca de la relación entre Maquiavelo-Montaigne. Primero, se encuentran los autores que afirman que Montaigne fue fuertemente influido por los escritos de Maquiavelo (se destacan los trabajos de: Sanders, 1976; Schaeffer, 1990; Borghi, 1991; Nicolai, 1957). El clásico trabajo de Sylvia G. Sanders muestra a Montaigne como un discípulo de Maquiavelo especialmente en torno a los problemas morales, la voluntad del príncipe como fundamento del derecho y una misma racionalidad en comprender los problemas políticos. En el caso de otro clásico texto de la literatura especializada como es el de Alexander Nicolai, se muestra un minucioso análisis para ilustrar con más radicalidad la influencia que tuvo Maquiavelo en Montaigne. Nicolai analiza con atención el ensayo "Lo útil y lo honesto" y concluye que Montaigne se siente seducido por las ideas de Maquiavelo. Asimismo, el estudio de Giulaniano Borghi aborda como lo trágico es una matriz de mirada del mundo que comparten tanto Maquiavelo como Montaigne

Segundo, se hallan aquellos/as que ponen a Montaigne como contrafigura de Maquiavelo (Shklar, 1982; Grady 2002, 2006; Villey, 1969). En el caso de Judith Shklar se observa una tajante contraposición entre Montaigne y Maquiavelo en torno al lugar del uso de la crueldad. Para Shklar, la separación que hace Maquiavelo entre moral y política resulta intolerable para Montaigne. Por más que Montaigne reconoció que había muchas cosas moralmente malas que se hacían en política, jamás las llamó correctas y, según Shklar, Montaigne no podía aceptar como inevitables esas crueldades. Dentro de este grupo de especialistas que son tajantes en marcar la diferencia entre Maquiavelo y Montaigne, se destacan los recientes estudios de Hugh Grady que posicionan a Montaigne como el teórico renacentista de la resistencia. La 
complejidad de Montaigne reside en las múltiples perspectivas que habitan en su obra, característica que también comparte con William Shakespeare. En relación con Maquiavelo, los Ensayos de Montaigne dan cuenta de una subjetividad no fijada y disputan con la comprensión que tiene el propio Maquiavelo de una subjetividad que es efecto del poder impersonal del príncipe ${ }^{5}$.

Por último, existen interpretaciones que muestran tanto las afinidades como las diferencias entre ambos autores (Rodríguez Rial, 2020; Zaharia, 2014; Burke 1985; Whitfield, 1973, 2002). En el clásico estudio biográfico que realiza Edmund Burke, Montaigne es emparentando con Maquiavelo en tres aspectos: primero, es calificado como un antiutopista, especialmente en lo relativo a la política; segundo, sabía de los poderes impredecibles que podía tener la diosa Fortuna al igual que el propio Maquiavelo; y, por último, era muy consciente que los príncipes tenían que utilizar medios malos para ejercer un buen fin. Sin embargo, para Burke, Montaigne se aleja de Maquiavelo en la referencia de "leyes generales y universales" para la política. En su reciente artículo "Miedos políticos. Emociones, sentidos y efectos en tres momentos de la teoría política", Gabriela Rodríguez Rial ubica a Maquiavelo y a Montaigne en un mismo linaje:

Tanto para Guicciardini como para Maquiavelo y Montaigne el miedo a la pérdida es compartido por quienes componen los cuerpos políticos independientemente del régimen político y del grupo o sector social al que pertenezcan. En los Discursos I.11 Maquiavelo (...) reconoce que la religión se asocia con un miedo específico y con Montaigne apunta al carácter sugestivo o imaginativo de los miedos que se origina en la falta o exceso de confianza de los hombres en sí mismos. Pero el escritor francés es el único de los tres que tematiza el terror pánico (Montaigne, 2011: 81- 82) (Rodríguez Rial, 2020, p. 127).

\footnotetext{
${ }^{5}$ Al respect Grady argumenta lo siguiente: "Similarly, of course, Montaigne has long been discussed as a possible source for a number of Shakespeare's ideas, with a similar lack of consensus, much of the problem revolving around the difficulty of identifying any unequivocal verbal echoes of Montaigne by Shakespeare until The Tempest. Here I will be assuming that such influences travelled discursively and need not have been direct to be meaningful. With that assumed, I will argue that Shakespeare's plays indeed display a multivalent reaction to both Montaignean and Machiavellian themes. In particular, Shakespeare's plays go beyond the logic of The Prince to critique certain of its premises and to explore the cultural crisis of meaning that its logic creates" (Grady, 2000, pp. 120-121)
} 
Hecha la reconstrucción de la literatura especializada, es necesario destacar que en este artículo se parte del tercer modo de abordaje para dar cuenta de un punto de contacto entre Maquiavelo y Montaigne poco estudiado: los caníbales. ¿Por qué los caníbales? Los caníbales es el arquetipo en el cual se construye "el otro", "lo bárbaro", "lo salvaje", "lo incivilizado" y "lo poco ilustrado". En las apariciones de los caníbales se restituye el advenimiento de América como una realidad central en donde gravita todo el sistema (Segato, 2015). Desde esta perspectiva, América no configura un espacio excéntrico para la construcción de un centro, sino que su emergencia (re)configura y origina el propio mundo moderno. En este sentido, la conquista de América no es un hecho menor, no solo para la geopolítica sino también para las categorías filosóficas y teóricas políticas.

Después de esta extensa introducción en la que se ha abordado, por un lado, de modo sucinto el hilo que conecta a ambos autores a través de la evidencia textual que Montaigne fue lector de Maquiavelo y, por otro lado, la literatura especializada que ha estudiado las tensiones y relaciones entre ambos autores, se dará cuenta de dos conexiones entre Maquiavelo y Montaigne no estudiadas dentro del campo de estudio, a saber: el protagonismo que tienen las costumbres en el modo de ser de los pueblos y la influencia que tiene la presencia de América, del Nuevo Mundo, y con ello la figura de los caníbales en la construcción de los escritos de estos dos autores. Una vez realizado esto, se explicitarán las conclusiones que se desprenden del trabajo realizado.

\section{La fuerza de las costumbres}

Montaigne comparte con Maquiavelo una sensibilidad común en torno a la fuerza de las costumbres que ejercen sobre los hombres. Para evidenciar dicha afirmación, en este apartado se analizará el capítulo XXII del primer libro de los Ensayos de Montaigne y una selección de la obra de Maquiavelo, especialmente se estudiarán los textos menos conocidos como son sus informes diplomáticos. 
En el ensayo "De las costumbres, y de no cambiar fácilmente una ley aceptada", Montaigne restituye una clásica tensión entre costumbre y naturaleza, entre lo artificial y lo natural:

Pues la costumbre es una maestra de escuela, violenta y traidora [violente et traîtresse]. Poco a poco establece en nosotros, sin que nos demos cuenta, las bases de su autoridad; pero pese a este comienzo dulce y humilde, una vez instalada y plantada con ayuda de tiempo, nos descubre luego con un rostro tiránico y furioso [un furieux et tyrannique visage], contra el cual ya ni tenemos la libertad de levantar los ojos. La vemos forzar de continuo todas las reglas de naturaleza (...) (Montaigne, 2011, p. 110) $)^{6}$.

La costumbre es puesta como la enemiga de la libertad. Es más, solemos entender como razonable solamente a todo hecho al que estamos habituados:

La costumbre adormece la visión de nuestro juicio. Los bárbaros no nos parecen más asombrosos que nosotros a ellos (...). La razón humana es un color que cubre y otorga parecido peso a todas nuestras opiniones y costumbres de cualquier tipo que sean: infinita en materia, infinita en diversidad (Montaigne, 2011, p. 113).

De esta manera, parece haber una reversibilidad de miradas: esos bárbaros que, vistos y considerados así, terminan siendo un espejo para quienes los ven. Sin embargo, no todo es negativo en la caracterización de la fuerza "tiránica" de las costumbres. Gracias a ellas, se pueden observar toda la multiplicidad y la diversidad que habitan en la humanidad. Por ejemplo, hay pueblos en los cuales las mujeres solteras embarazadas "pueden abortar con medicinas adecuadas (...) sin ningún tipo de ocultamiento" (Montaigne, 2011, p. 113) y también hay otros lugares "donde se ven prostíbulos de varones, y hasta casamientos entre ellos" (Montaigne, 2011, p. 113).

La descripción de las costumbres parece mostrarnos, de modo simultáneo, su fuerza violenta y lo plurales y distintas que pueden ser. Pero también las costumbres

\footnotetext{
${ }^{6}$ Las cursivas son nuestras.
} 
tienen un correlato en los modos de sujeción política. Para decirlo en otras palabras, las características culturales de una comunidad tienen una relación en cómo se obedece:

Los pueblos criados en la libertad y el autocomando estiman que cualquier otra forma de política es monstruosa y contra natura: los habituados a la monarquía hace lo mismo. (...) en el mismo momento en que con grandes dificultades se deshacen de la molestia de un amo, corren a colocar otro con iguales dificultades, porque no pueden resolverse a odiar la sujeción. Es por intervención de la costumbre que cada cual está contento con el lugar donde la naturaleza lo ha plantado (...) (Montaigne, 2011, pp. 116- 117).

Montaigne parece demostrar que las formas que tenemos los hombres y las mujeres de relacionarnos con nuestras instituciones están asentadas en costumbres, por no decir que se encuentran sobre una mera contingencia. Esta aseveración es, de hecho, bastante cercana a Maquiavelo quien, en el capítulo $V$ de El príncipe, reconocía la dificultad que tenía un príncipe para poder administrar una ciudad "acostumbrada a vivir con sus propias leyes" ya que ella siempre habita la "memoria de la antigua libertad" (Maquiavelo, 2012, p. 23). Por el contrario, las ciudades "acostumbradas" a vivir bajo el dominio de un príncipe están más habituadas a obedecer. En la misma sintonía, en el capítulo IV del primer libro de los Discursos sobre la primera década de Tito Livio, Maquiavelo diferencia aquellos pueblos acostumbrados a vivir en libertad de aquellos que están acostumbrados a vivir en servidumbre: "Además los deseos de los pueblos libres rara veces son dañosos a la libertad, porque nacen, o de sentirse oprimidos, o de sospechar que pueden llegar a estarlo" (2000, p. 43).

De esa distinción se deduce que en las ciudades en las cuales se encuentran pueblos serviles, resulta más difícil la instauración de un orden que acoja la libertad. En el capítulo XVII del mismo libro, parece surgir una cierta predisposición del pueblo (que no quería ser dominado) a dejarse dominar para terminar poniéndose el mismo "el yugo" en el cuello: 
$\mathrm{Y}$ debe tomarse como presupuesto certísimo que una ciudad corrompida que viva bajo un príncipe no podrá llegar a ser libre, aunque ese príncipe desaparezca con toda su estirpe, por lo que conviene que un príncipe suceda a otro, pues no descasará hasta crear un nuevo señor (...) (Maquiavelo, 2000, p.86).

Estas premisas generales cobran mayor volumen en las descripciones minuciosas que se encuentran en los informes sobre las misiones diplomáticas ${ }^{7}$. Entre 1498 a 1512, Maquiavelo ocupó formalmente el cargo de secretario de la Segunda Cancillería y el de la Secretaría de los Dieci di Balia que le permitió ser parte de grandes eventos diplomáticos de envergadura del período, a saber: las cuatro misiones en Francia (1500, 1503, 1510 y 1511), los dos encuentros con Cesar Borgia (entre 1502 y 1503), las dos misiones en la corte papal (1503 y 1506) y la embajada en la corte imperial (1507-1508). Como señala Bausi (2015), al salir de Florencia y poder socializar con las figuras de envergadura internacional de la época, Maquiavelo pudo ampliar sus visiones analíticas para entender la realidad política que le tocaba habitar. En los informes dedicados a Francia (Del carácter de los franceses y Retrato de los asuntos de Francia escritos entre 1500-1511) observa como la experiencia en ese país, donde Maquiavelo estuvo en cuatro oportunidades, le permitió dilucidar la fortaleza de la monarquía. En el caso de las minutas dedicadas a Alemania (Informe sobre los asuntos de Alemania realizado el día 17 de junio de 1508; Discurso sobre los asuntos de Alemania y sobre el Emperador de 1509 y Retrato de los asuntos de Alemania de 1512), se observa un mismo ejercicio etnográfico. La primera experiencia de Maquiavelo en Alemania ocurre en 1507 cuando es enviado por Soderini (luego de muchas negociaciones con los ottimati que se oponían que vaya un hombre de confianza del gonfaloniero y a favor de la política filofrancesa) para que observe la Dieta de Constanza frente a un rumor que anunciaba que el emperador Maximiliano de Habsburgo planeaba invadir a Italia (Bausi, 2015, pp.50-61).

\footnotetext{
${ }^{7}$ Como señala Francesco Bausi (2015, pp. 97-123) en su ya clásico libro, estos textos que se abordaran este apartado se encuentran clasificados como "escritos menores" y tocan plurales temas (desde informes diplomáticos hasta militares). Lo que permite reunirlos en un mismo registro es que, como dice Bausi, todos son escritos en la coyuntura política.
} 
En las minutas dedicadas a los franceses, Maquiavelo efectúa una recopilación de pautas y axiomas sobre los hábitos que tiene esta comunidad. Es decir, observa y sistematiza las evidencias empíricas del trabajo diplomático: "Por naturaleza, los franceses son más feroces que fuertes o hábiles" (Maquiavelo, 1991, p. 43), pero también pueden mostrarse humildes frente a quienes manifiestan una resistencia a su poder. Son "humildes en la desgracia" pero "insolentes en la buena suerte" (1991, p. 38). Es más, los franceses pueden dimitir frente a cualquier infortunio que les ocurra como sucedió con la derrota en la batalla en el Garellano en 1503. Para Maquiavelo, Francia es vista como país pródigo: tiene una gran extensión y variedad de tierras. Salvo en vestimentas, sus nobles no gastan mucho el dinero que recogen del pueblo porque tienen el alimento disponible. Estas observaciones parecen demostrar el interés que tiene Maquiavelo por la diversidad cultural (Landi, 2017) y, al igual que Montaigne, la sensibilidad y la apertura por los plurales modos de ser en el mundo. En este horizonte, el florentino observa desde sutiles gestos ("gastan poco en vivir"; "visten toscamente") hasta las maneras que tienen los pueblos de relacionarse con su representante ("Los pueblos de Francia son humildes y obedientes y tienen gran veneración por su rey").

Otro viaje significativo que cumple Maquiavelo y que resulta interesante para los efectos de este artículo es el que realiza a Bolzano a principios de 1508 , después de varios conflictos institucionales. En la minuta de ese viaje da testimonio de aquello que oyó: "Habiendo estado en ese lugar y habiendo oído razonar tantas veces"; "no teniendo más ocupación que esa, describiré todas las cosas que he oído" (Maquiavelo, 1991, p. 60). Nuevamente se nos presenta un Maquiavelo etnógrafo que observa y sistematiza los datos de la experiencia:

Y si digo que los pueblos de Alemania son ricos es porque así es verdad; y lo que los convierte en adinerados es que viven como pobres, porque ni edifican, ni gastan en vestir, ni poseen enseres en sus casas y les basta con tener pan y carne en abundancia y una estufa para protegerse del frío. El que no posee más cosas prescinde de ellas y no las busca. Gastan en sí mismo dos florines cada diez años, y cada cual vive en tal 
proporción según su rango y nadie se preocupa por lo que le falta, sino por lo que necesita, y sus necesidades son mucho menores que las nuestras (1991, pp. 62-63).

Entonces, el pueblo alemán se presenta con una personalidad austera ("ni gastan en vestir ni poseen enseres en sus casas y les basta con tener pan y carne en abundancia y una estufa para protegerse del frío") que lo diferencia de los italianos ("gastan en sí mismos dos florines cada 10 años, y cada cual vive en tal proporción según su trabajo y nadie se preocupa por lo que le falta, sino por lo que necesita, y sus necesidades son mucho menores que las nuestras"). Hay algo del hábito a la austeridad que conduce a los alemanes a tener una vida rústica.

Como notamos en el ensayo de Montaigne, en estas minutas de Maquiavelo también hay algún tipo de sincronía entre las características culturales de esa comunidad y el tipo de sujeción política que se concibe. En esta descripción, el florentino narra la singularidad del pueblo alemán que no quiere ir a la guerra porque se encuentra bien con el modo de vida que lleva. Llegado el caso, si tiene que ir a la guerra lo hará, pero bajo sus condiciones, es decir, que se les pague "en abundancia". La representación de los alemanes a través de sus costumbres y hábitos bajo la pluma de Maquiavelo visibiliza el contraste con "la gran veneración" que sienten los franceses por el rey. Esa contraposición muestra, a su vez, cómo las costumbres pueden moldear la forma de ser de los pueblos, su temperamento y su modo de relacionarse con la obligación política.

Esta conexión que se observa entre la sujeción política y las costumbres que adquieren una comunidad, habilita un resquicio para analizar la figura de los "caníbales" en algunos pasajes de los textos de los autores. De esta manera, en el próximo apartado se analizará el ensayo "De los caníbales" (I.30) de Montaigne y, más allá del prefacio de los Discursos sobre la primera década de Tito Livio, se abordará unos pasajes de Historias de Florencia de Maquiavelo.

\section{El Nuevo Mundo y la antropofagia}

Montaigne al igual que Maquiavelo escapa de cualquier estereotipo. Fue un político, pero también un historiador, filósofo y hasta un precursor de la literatura del yo. Pero 
si pudiéramos tomar una licencia sobre esta afirmación, se podría llegar a decir que Montaigne se asemeja a un "etnógrafo". En gran parte, los Ensayos son un testimonio de una sensibilidad antropológica; de oír y ver lo diverso y dejar oír y dejarse ver. En el capítulo siete de su libro dedicado a Montaigne, Burke (1985) muestra que una de las cosas más sorprendentes de este autor para lectores y lectoras del siglo $X X-Y$, podemos agregar, también para el siglo XXI- es su curiosidad por otras culturas.

En "Sobre los Caníbales", Montaigne se asemeja a un etnógrafo o a un viajante que describe todo aquello que lo asombra del nuevo mundo. La descripción de los habitantes de Brasil es minuciosa: se centra en cómo son sus viviendas, sus artefactos domésticos, sus rituales, sus bebidas, en definitiva, su cotidianeidad. "Su bebida está hecha de maíz, tiene el color de nuestros vinos claros y la beben tibia" (Montaigne, 2011, p. 193) y "sus camas son un tejido de algodón colgado del techo como las de nuestros navíos". Más adelante, agrega de modo conciso que "pasan el día bailando". Hay división de tareas según las edades de los perteneciente a la comunidad. Los más jóvenes "salen a cazar animales con arcos", algunas mujeres "se ocupan de calentar la bebida" y los más ancianos "predican en común a todos" (Montaigne, 2011, p. 193). Aunque para el autor de los Ensayos viajar era la mejor educación porque te permitía conocer lo diverso y lo desconocido como se observa en De la vanidad (III.9), jamás viajó a América. Ese hecho no le impidió describir con una notable perspicacia las imágenes de esos habitantes de las nuevas tierras. Un ejemplo ilustrativo es cuando señala que estos hombres se encontraban rasurados por todas partes y que, de hecho, se afeitaban mejor que él mismo con una simple navaja de madera:

Van totalmente afeitados, mucho más al ras que nosotros, sin otra afeitadora que no sea de madera o piedra. Creen que las almas son eternas, y que aquellas que lo han merecido de parte de los dioses se alojan en el lugar en que se levanta el sol (...) Tienen no sé que sacerdotes y profetas que rara vez se presenta ante el pueblo, pues viven en las montañas (Montaigne, 2011, p. 194).

Con todo esto, Montaigne parece mostrar dos cosas: por un lado, la sensibilidad por la alteridad y la diversidad; por otro lado, en el uso de la comparación 
esos habitantes no parecen tan singulares y extraños. Es más, se niega llamarlos bárbaros porque "cada uno llama barbarie a lo que no es su costumbre" (Montaigne, 2011, p. 91). Esta frase toma más radicalidad si recordamos que los españoles habían denotado como caníbales a los indios para poder justificar la esclavitud y, hasta cierto punto, la apología de los caníbales resulta ser una crítica a la política española.

Cuando realizaban las guerras, los indios se encontraban siempre desnudos y traían la cabeza del enemigo que habían matado. Una vez que estaba muerto, "lo asan y lo comen todos juntos y envían algunos pedazos a los amigos que están ausentes". Esta narración podría ocasionar una indignación en nuestros espíritus. Pero descubrimos que el efecto buscado es otro cuando leemos: "No me irrita que señalemos el bárbaro horror que hay en semejante acción, pero sí señalando tan claramente sus errores, seamos tan ciego ante los nuestros" (Montaigne, 2011, p. 195). Hay una reversibilidad en las prácticas que observamos; es decir, en ellas se proyectan aquello que también habita en nosotros mismos. De esta manera, Montaigne muestra cómo "los europeos", encumbrados desde una civilización occidental, pueden ser también caníbales:

(...) pienso que hay más barbarie en comerse a un hombre vivo que en comérselo muerto y en desgarrar con tormentos y torturas un cuerpo aun sensible, asarlo poco a poco, darlo a los perros y los cerdos (tal como no solo lo hemos leído, sino visto hace muy poco, no entre enemigos antiguos sino entre vecinos y conciudadanos y peor aún, so pretexto de piedad y religión) (Montaigne, 2011, p. 195).

Si quedaba alguna duda sobre esta postura tan radical y potente, más adelante, Montaigne agrega: "Incluso podemos llamarlos bárbaros con respecto a las reglas de la razón, pero no con respecto a nosotros, que los superamos en todo tipo de barbarie" (2011, pp-195-196). Esta referencia a los caníbales, a su vez, demuestra el interés por las costumbres extrañas y novedosas que tenía el autor de los Ensayos. Como da cuenta Burke (1985), Montaigne parece haber conocido bien la vida de los habitantes de Brasil a través de los relatos de unos viajeros franceses, André Theyet y Jean de Léry. A diferencia de Thevét que veía en los habitantes del Nuevo Mundo la 
encarnación de bestias ateas, en la descripción de Jean de Léry los habitantes eran considerados como bárbaros, pero humanos al fin. En sus crónicas, Léry termina condenando la Matanza de San Bartolomé y otras "salvajadas" de las guerras religiosas francesas. En este sentido, este diagnóstico parece haber sido de inspiración para Montaigne, pero en un sentido renovado y más radical. En una línea argumental, el ejemplo de los caníbales le servirá para hablar de la propia barbarie y, en la otra línea argumental, para defender un relativismo cultural.

A diferencia de Montaigne, Maquiavelo jamás hizo una referencia explícita a la conquista de América. Sin embargo, como se ha advertido, Maquiavelo parece utilizar una metáfora del Nuevo Mundo en los Discursos sobre la primera década de Tito Livio:

\begin{abstract}
Aunque por la naturaleza envidiosa de los hombres la tarea de buscar nuevos modos y órdenes nuevos [modi e ordini nuovi] haya sido siempre tan peligrosa como buscar aguas y tierras ignotas [acqua e terre ignote], porque todo está más dispuesto a denostar que a loar las acciones ajenas, sin embargo, llevado de ese deseo que siempre ha existido en mí de obrar sin ningún respeto [senza alcuno rispetto] en aquellos asuntos que me parecen beneficiosos para todos, me he decidido a entrar por un camino que, como no ha sido aún recorrido por nadie [non essendo suta ancora da alcuno trita], me costará muchas fatigas y dificultades, pero también la recompensa de aquellos que consideran humanamente el fin a que se enderezan mis trabajos (Maquiavelo, 2000, p. 27).
\end{abstract}

Así, en el proemio de los Discursos sobre la primera década de Tito Livio, Maquiavelo parece realizar un paralelismo entre dos registros diferentes: el de la política ("modi e ordini nuovi") y el de la geografía ("acqua e terre ignote"). Son dos campos disciplinares que, si bien parecen ser distintos, están ambos caracterizados en torno a la idea de lo nuevo. Hay una afinidad, entonces, entre el descubrimiento filosófico político y el descubrimiento geográfico. Si bien Leo Strauss (1978) ha escrito que Maquiavelo parece ser el nuevo Cristóbal Colón de la filosofía política ${ }^{8}$, Oreste

\footnotetext{
${ }^{8}$ Para Leo Strauss, Maquiavelo se presenta como descubridor de nuevos continentes, es decir, como fundador de la modernidad y a la vez, como el que corrompe la Tradición. Al respecto, Gronte señala que Maquiavelo puede es el fundador de la modernidad porque "reemplaza el mito antiguo con la
} 
Tommansini ha indicado mucho tiempo antes que la frase "buscar aguas y tierras ignotas" alude a los escritos de Américo Vespucci (Tommasini, 1883-1991, p. 477). Como documenta Landi (2017), es necesario preguntarse si Maquiavelo tenía algún tipo de conocimiento sobre los viajes emprendidos a América o si existía en su biblioteca algún libro sobre las crónicas. En efecto, para sorpresa de muchos estudiosos, en el archivo de la familia Machiavelli de la Biblioteca Central de Florencia, se encuentra un documento de Simone Verde, un mercader florentino que acompañó a Cristóbal Colón a América y que testimonia sobre los viajes. Para Landi (2017), este texto pudo haber sido leído por Maquiavelo y, sobre todo, puede ser una pista para repensar las metáforas por éste utilizadas en el proemio, es decir, tratar de dilucidar si en el paralelismo que realiza Maquiavelo entre nuevos órdenes/nuevas aguas y filosofía política/geografía se puede visibilizar algún tipo influencia de lo que estaba sucediendo en América.

Como se mencionó al comienzo, el modo por el cual Maquiavelo y Montaigne comprendieron a la figura de los caníbales del Nuevo Mundo nos brinda una pista sugerente para pensar desde otra óptica los vínculos políticos. En este sentido, retomaremos una hipótesis de la lectura de Sandro Landi (2017, pp. 113-128) en torno a las figuras de Simone Verde y Agostino Vespucci. En las cartas de Simone Verde se testifican por primera vez las prácticas de canibalismo en una isla del Caribe. Esto colabora a pensar que cuando Maquiavelo escribía y pensaba lo hacía en un contexto en el cual se recibían noticias sobre los antropófagos del Nuevo Mundo. Una de las hipótesis más interesantes de Landi es que Maquiavelo parece haber leído las cartas de Vespucci sobre las otredades del nuevo mundo 9.

propaganda moderna. El Príncipe proclama abiertamente lo que los antiguos discutían discretamente, y solo en las voces de personajes de dudosa reputación como Trasímaco" (Grote, 1998:121).

${ }^{9}$ Según Landi (2017) el 4 de junio de 1501, Vespucci envió una carta desde Cabo Verde a Lorenzo di Pierfrancesco de Médicis para relatarle la expedición de Cabral a las Indias Orientales. En ella menciona a menciona a Gherardo Verde, hermano de Simone, como portador de la carta y testigo. En los años siguientes, Vespucci continuó escribiendo a sus clientes y amigos en Florencia. Actualmente contamos con cartas: la primera (en traducción latina), dirigida a Lorenzo, se conoce como Mundus novus (1503); la segunda está dirigida a Piero Soderini (Carta de las Islas Recién Descubiertas, 1505). Como Maquiavelo trabajaba con Soderini en aquellos años, la hipótesis de Landi es muy pertinente porque puede parecer cierto que el florentino se haya topado con esos textos. 
En Historia de Florencia (1520-1524) Maquiavelo (2009) analiza la historia de su ciudad, Florencia, una ciudad que jamás pudo ser Roma y que estuvo atravesada por continuas facciones. En una parte de la narración, Landi (2017: 126-128) marca que hay una referencia a la antropofagia relacionada con la expulsión del Duque de Atenas, que tuvo lugar en julio de 1343 en donde se resalta la masacre del podestà Guglielmo de Asís y de su hijo de dieciocho años. En su relato, Maquiavelo casi sigue al pie de la letra la Crónica de Giovanni Villani (siglo XIV), sin embargo, como siempre, modifica algo y agrega algunos detalles que podría espantar a cualquier lector y lectora:

Ya para que todos los sentidos se sacarían en la venganza, después de haber oído sus lamentos de haber visto sus heridas y de haber tocado sus carnes laceradas, querían también que su paladar los saborease, a fin de que, una vez saciados los sentidos más externos, se saciaran también sus entrañas (Maquiavelo, 2009, p.131).

Saborear la carne lacerada de los enemigos remite a las crónicas de Vespucci que, a partir del siglo XVI, se convirtieron en un arquetipo común para representar la bestialidad que habitaba en el Nuevo Mundo. Este hecho no es insignificante porque permite borrar abruptamente la distancia entre las sociedades tribales y la sofisticada sociedad urbana cuyos profundos mecanismos se ponen de manifiesto por la guerra civil endémica. En ambos casos, la guerra y la consiguiente devastación de los enemigos permite fundar o refundar, como en el presente caso, la comunidad política.

El imaginario del Nuevo Mundo también interviene en un famoso pasaje del tercer libro de Historia de Florencia. Ahí se encuentra la revuelta de los Ciompi (1378) en la cual un líder anónimo exhorta a sus compañeros a no detener la insurrección. Para convencer a su público, el orador anónimo recurre en dos casos a argumentos asociados a imágenes que circulan en el Nuevo Mundo: desnudez, falta de bienes, canibalismo. El binomio desnudez-igualdad, claramente descrito por Vespucci, es interpretado en un sentido político por el ciompo:

Si nos quedáramos todos completamente desnudos veríais que somos iguales a ellos que nos vistan a nosotros con sus trajes y a ellos con los nuestros; y, sin duda alguna, 
nosotros pareceremos los nobles y ellos los plebeyos; porque son solo la pobreza y las riquezas las que nos hacen desiguales (Maquiavelo, 2009, p. 161).

La segunda referencia implícita al Nuevo Mundo en el discurso del líder ignoto se nota cuando, en la descripción desoladora de las tensiones entre ambiciones de unos y fragilidad de otros, aparece lo siguiente: "De aquí nace el que los hombres se comen unos a otros (mangiarsi l'un l'altro) y que el más débil se lleve siempre la peor parte" (Maquiavelo, 2009:162). Esta imagen de la antropofagia sobre la representación de los habitantes del Nuevo Mundo se resignifica en los discursos de Maquiavelo, pero que, como Montaigne, toma un sentido muy novedoso.

A través de la restitución de una selección de los Discursos y de Historia de Florencia se buscó evidenciar la influencia que originó el advenimiento del Nuevo Mundo en la escritura maquiaveliana. Desde la referencia al descubrimiento de nuevas y desconocidas tierras en el proemio de los Discursos, hasta la imagen de la antropofagia en Historia de Florencia para caracterizar las tensiones que habitan en los vínculos sociales en esa ciudad, permitieron dilucidar respecto de cómo el descubrimiento de América galvanizó nuevas categorías conceptuales.

Las noticias que llegaban sobre América han contribuido a una nueva lectura del mundo: desde el canibalismo como simple fenómeno tribal hasta la metáfora de las relaciones políticas y sociales. Tanto para Maquiavelo como para Montaigne la imagen del caníbal que era tradicionalmente vista como un "otro" salvaje es introyectada al mundo europeo y, en ambos casos, en relación con una guerra civil.

\section{Conclusiones}

A lo largo de este artículo se buscó indagar la conexión que existe entre Nicolás Maquiavelo y Michel de Montaigne. A partir de la evidencia clara que Montaigne leyó a Maquiavelo y de los estudios realizados por un amplio espectro de la literatura especializada abordados en la introducción, se trató de dar cuenta del hilo que une a ambos autores en un registro doble: por un lado, reconocer el modo por el cual las costumbres de los pueblos son un elemento relevante para entender cómo se dan las dinámicas políticas; por otro lado, dilucidar la presencia en ambos autores del Nuevo 
Mundo a través de la figura de los caníbales, de un modo obvio en Montaigne y de un modo más sutil en Maquiavelo.

Cabe reiterar una vez más que, como se señaló en la introducción, Montaigne como lector del florentino fue un tópico muy estudiado por la literatura especializada, pero el hilo que los vincula a través de la imagen de la antropofagia del Nuevo Mundo no fue para nada trabajado. Solo Sandro Landi (2017) ha llamado la atención de la presencia gravitante de América en los escritos de Maquiavelo. Al explorar la presencia del "otro" salvaje en ambos autores, se pudo descubrir una afinidad mucho más profunda, una sensibilidad común en los modos de entender los dilemas de vivir en una comunidad fracturada por guerras civiles y atrocidades. Se pudo evidenciar un modo común de mirar y entender las sociedades y las dinámicas de sujeción política.

Como se trató de demostrar a lo largo de este trabajo, hay un hilo que conecta a Montaigne con Maquiavelo desde un registro etnográfico, es decir, desde las descripciones sobre los habitantes del Nuevo Mundo que realiza Montaigne hasta los retratos que dibuja Maquiavelo sobre los alemanes y franceses. A través de la lectura de estos autores de la temprana modernidad, pudo entreverse cómo la noción de "América" o el Nuevo Mundo resultó ser una identidad creada. América no sé configuró como un espacio excéntrico para la construcción de un centro, sino que su emergencia (re)configuró y originó el propio mundo moderno. La conquista de América no es un hecho menor no solo para la geopolítica sino también para las categorías filosóficas y teóricas políticas.

En definitiva, y para decirlo una vez más, las descripciones de las prácticas antropofágicas de los habitantes del Nuevo Mundo, presentes más explícitamente en Montaigne y de un modo implícito en Maquiavelo, resultaron ser una metáfora de las relaciones políticas y sociales en un sentido más general. Demostraron que, a diferencia de como argumentó H. Gary Grand, Maquiavelo y Montaigne parecen compartir un mismo modo de entender las subjetividades y los vínculos, más flexibles y no de un modo sustancialista. Para decirlo en otras palabras, la antropofagia fue otra costumbre más que en su propia reversibilidad resultó ser espejo de atrocidades más propias. 


\section{Bibliografía}

Bausi, F. (2015). Maquiavelo. (Trad. M. Barbuto). València: PUV Universitat de València.

Borghi, G. (1991). La politica e la tentazione tragica: la" modernità" in Machiavelli, Montaigne e Gracian. Milan: Franco Angeli.

Burke, P. (1985). Montaigne. (Trad. V. Peña) Madrid: Alianza.

Desan, P. (2016). The Oxford handbook of Montaigne. Oxford: Oxford University Press.

Fournel, J. \& Zancarini, J. (2020). Machiavel. Une vie en guerres. Paris: Passés Composés.

Grady, H. (2002). Shakespeare, Machiavelli, and Montaigne: Power and Subjectivity from Richard II to Hamlet. Oxford: Oxford University Press.

Grady, H. (2006). Afterword: Montaigne and Shakespeare in Changing Cultural Paradigms. The Shakespearean International Yearbook: Shakespeare and Montaigne Revisited. Ed. Peter Holbrook. Vol. 6. Ashgate.

Grote, J. (1998). The Founding Murder in Machiavelli's The Prince. Journal of Violence, Mimesis and Culture, 5 (Spring), 118-134.

Landi, S. (2017). Lo sguardo di Machiavelli. Una nuova storia intellettuale. Bolonia: II Mulino.

Machiavelli, B. (2007). Libro di Ricordi. (al cuidado de Olschki Cesare). Roma: storia e letteratura casa editrice.

Machiavelli, N. (1971) Tutte Le Opere. (al cuidado de Mario Martelli). Firenze: Sansoni.

Maquiavelo, N. (2000). Discursos sobre la primera década de Tito Livio (Trad. A. Martínez Arancon). Madrid: Alianza.

Maquiavelo, N. (1991). Escritos políticos breves. (Trad. M. T. Navarro Salazar). Madrid: Tecnos.

Maquiavelo, N. (2009). Historia de Florencia. (Trad. F. Fernández Murga) Madrid: Tecnos.

Maquiavelo, N. (2012). El príncipe (Trad. I. Costa). Buenos Aires: Colihue.

Maquiavelo, N. (2013). Epistolario 1512-1527. (Trad. S. Mastrangelo) México D.F.: FCE.

Montaigne, M. (2011). Ensayos. (Trad. G. Isnardi) Madrid: Losada.

Montagine, M (1965). Essays. Paris: Gallimard.

Montaigne, M (2007). Ensayos. (Trad. Bayod Brau) Barcelona: El Acantilado.

Nosetto, L. (2020) El estado en la teoría política de la temprana modernidad. Anacronismo e Irrupción, Vol. 10, №18, pp. 173-204.

Panichi, Nicola (2006). "Au-delà de la vertu 'innocente': Montaigne et les théoriciens de la raison d'état." Montaigne politique. Ed. Phillippe Desan. Paris: Honore Champion.

Rodríguez Rial, G. (2020). Miedos políticos. Emociones, sentidos y efectos en tres momentos de la Teoría Política. Anacronismo e irrupción. Vol. 10, N¹9, pp. 120-148.

Sanders, S. (1976) Montaigne et les idees politiques. Bulletin de la Société des Amis de Montaigne, 18-19.

Schaeffer, D. (1990). The Political Philosophy of Montaigne. Ithaca: Cornell UP. 
Segato, R. L. (2015). La crítica de la colonialidad en ocho ensayos y una antropología por demanda. Buenos Aires: Prometeo.

Shklar, J. (1982). "Putting Cruelty First" Daedalus, Summer, 11(3), Representations and Realities. pp. 17-27.

Skinner, Q. (1978) The Foundations of Modern Political Thought. Vol. II: The Age of Reformation. Cambridge: University Press.

Strauss, L. (1978). Thoughts on Machiavelli. Chicago: The University of Chicago Press.

Tommasini, O. (1883-1911). La vita e gli scritti di Niccolò Machiavelli nella loro relazione col machiavellismo. Storia ed esame critico. Roma: Loescher.

Villey, P. (1969). Les sources et l'evolution des Essais de Montaigne. Paris: Hacette.

Viroli, M. (2000). La sonrisa de Maquiavelo. (Trad. A. Pentimalli) Barcelona: Tusquets.

Vivanti, C. Maquiavelo. Los tiempos de la política. (Trad. M. T. Navarro Salazar). Buenos Aires: Paidós, 2013.

Whitfield, J H. (2002) Shakespeare, Machiavelli and Montaigne: Power and Subjectivity from Richard II to Hamlet. Oxford: Oxford UP,

Whitfield, J. H. (1973). Machiavelli Guicciardini Montaigne. Italian Studies, 28(1), 31-47

Zaharia, Oana-Alis (2014). Michel de Montaigne's Response to Machiavelli's II Principe. East-West Cultural Passage, (2), 7-28. 